\title{
Manufacturing Inventory Model for Deteriorating Items with Maximum Lifetime under Two-Level Trade Credit Financing
}

\author{
Dharmendra \\ Yadav \\ Dept. of Mathematics \\ Vardhaman College \\ Bijnor-246701 (U.P), \\ India
}

\author{
S.R. Singh \\ Dept. of Mathematics \\ CCS University \\ Meerut-250001(U.P), \\ India
}

\author{
Meenu Gupta \\ Dept. of Mathematics \\ Banasthali University \\ Banasthali-304022 \\ (Rajasthan), India
}

\author{
Dhanpal Singh \\ Dept. of Mathematics \\ Keshav Mahavidyala \\ Pitampura-110034 \\ (Delhi), India
}

\begin{abstract}
In the present study, an inventory model is developed especially for a manufacturer where manufactured product not only deteriorates continuous but also has a maximum lifetime. It is assumed that supplier offers full trade credit period of $\mathrm{M}$ to the manufacturer while due to the strong position in the market, manufacturer provides partial trade credit period of $\mathrm{N}$ to his/her wholesaler. The objective of the problem is to minimize the total inventory cost. By applying convex fractional programming results, necessary and sufficient conditions are obtained to obtain an optimal solution. Few theorems have been developed to determine manufacturer's optimal policies. Teng (1985), Teng (2002), Huang (2003), Teng and Goyal (2007), Chen and Teng (2014), and $\mathrm{Wu}$ and Chan (2014) are special case of our proposed model. Theorems are illustrated with the help of numerical examples. In addition, some managerial insights on the basis the numerical examples are also concluded.
\end{abstract}

\section{Keywords}

Manufacturer, Two-level supply chain, deterioration, lifetime

\section{INTRODUCTION}

Nowadays management of deteriorating items during inventory management has received considerable attention. Many researchers has been developed different inventory model for deteriorating items such as high-tech product, fruits, vegetables, medicine, volatile liquids, blood blanks, fashion goods, electronic components and others which deteriorate continuously due to evaporation, loss of utility, loss of marginal value of a commodity, obsolescence, spoilage and etc. The problem of managing deteriorating inventory is complex for a variety of reasons as the lifetime of the manufactured product is finite and starts to deteriorate once they manufactured. Ghare and Schrader (1963) were the first researchers for developing an inventory model with an exponential deterioration rate. They categorized decaying items into three types: direct spoilage, physical depletion and deterioration. Then Covert and Philip (1973) generalized Ghare and Schrader's constant exponential deterioration rate to a two-parameter Weibull distribution. Dave and Patel (1981) developed an EOQ model for deteriorating items by considering time-proportional demand. Goyal and Giri (2001) reviewed the trends in modeling of deteriorating items. Teng et al. (2002) generalized the EOQ model for deteriorating items with time-varying continuous demand. Dye et al. (2007) had considered an infinite time horizon and developed inventory model for single product where demand and deterioration rate were continuous and differentiable function of price and time respectively. In addition they had considered that shortages were completely backlogged. Min et al. (2010) presented an EOQ model for deteriorating items under stock-dependent and two-level trade credit. Yadav et al. (2012) developed multi-item inventory model for deteriorating items with stock dependent demand under twowarehouse system under inflation and time value of money. Chen et al. (2013) investigated an economic production quantity model for deteriorating items with two level trade credit financing. Chen and Teng (2014) developed and EOQ model for a retailer when his/her product deteriorates continuously and has a maximum lifetime and assumed that his/her suppler offers a trade credit. They determined the optimal replenishment period so that the total associated inventory cost is minimum. Bhunia et al. (2014) developed an inventory model for single deteriorating items with trade credit. They assumed that demand is constant and shortages are allowed and partially backlogged. Tayal et al. (2015) developed an inventory model for seasonal products with Weibull rate of deterioration having two potential markets say primary market and alternate market.

Due to globalization of market, there is a fierce competition among the organization to promote their business. Now, the organizations are taking serious attempt to manage inventories to get the competitive advantages over the other organization. Thus, the manager of every organization increasing their interest in optimizing the inventory decisions in a holistic way. As a result, they provide different types of facilities to others such as trade-credit. During trade-credit period, the manufacturer can sell the manufactured goods and earn the interest on the accumulated revenue received, and delay the payment up to the last moment of the trade credit allowed by the supplier. However, if the payment is not paid within the trade credit, then interest is charged on the outstanding amount under the previously agreed terms and conditions. This brings some economic advantage to the manufacturer as they may earn some interest from the revenue realized during the period of trade credit. By doing so, they get competitive advantages to other players in the market.

In this regard, a number of research papers become visible which deal with the economic order quantity problem under the condition of permissible delay in payments. Goyal (1985) is the first researcher to consider the economic order quantity (EOQ) inventory model under the condition of trade credit. Chand and Ward (1987) analyzed Goyal's model under assumptions of the classical economic order quantity model, obtaining different results. Goyal (1985) was extended by 
Shinn et al. (1996) and considered quantity discount for freight cost. Huang (2004) investigated that the unit purchasing price and the unit selling price are not necessarily equal within the EPQ framework under a supplier's trade credit policy. Teng et al. (2005) presented the optimal pricing and lot sizing model under permissible delay in payments by considering the difference between the purchase cost and the selling price and demand is a function of price. There are several relevant and interesting papers related to trade credit such as Chung et al. (2005), Mahata and Goswami (2007), Shastri et al. (2014), Singh et al. (2014), Bera et al. (2014), Yadav et al. (2015) and Rao and Rao (2015) and their references. All the above inventory models implicitly assumed one-level trade credit financing, i.e. it is assumed that the supplier would offer the manufacturer a delay period and the manufacturer could sell the goods and accumulate revenue and earn interest within the trade credit period. They implicitly assumed that the wholesaler would pay for the items as soon as the items are received from the manufacturer. That is, they assumed that the supplier would offer the manufacturer a delay period but the manufacturer would not offer any delay period to his/her wholesaler. In most business transactions, this assumption is unrealistic. Usually the supplier offers a credit period to the manufacturer and the manufacturer, in turn, passes on this credit period to his/her wholesaler. Huang (2003) proposed an inventory model assuming that the retailer also permits a credit period to its customer which is shorter than the credit period offered by the supplier, in order to stimulate the demand. Huang's (2003) was extended by Huang (2006) model to investigate the retailer's inventory policy under two levels of trade credit and limited storage space. Mahata and Goswami (2007) developed an inventory model to determine an optimal ordering policy for deteriorating items under two-level trade credit policy in the fuzzy sense. Huang (2007) incorporated Huang's (2003) model to investigate the two-level trade credit policy in the EPQ frame work. Liao (2008) developed an economic order quantity (EOQ) model with noninstantaneous receipt and exponentially deteriorating items under two level trade credit financing. Ho et al. (2008) developed supplier-buyer inventory model with the assumption that demand is sensitive to retail price and the supplier adopts a two-part trade credit policy. Tsao (2009) developed an economic order quantity (EOQ) model under advance sales discount and two-echelon trade credits. Huang's (2003) was modified by Kreng and Tan (2010) by developing optimal wholesaler's replenishment decisions in the economic order quantity (EOQ) model under two levels of trade credit policy depending on the order quantity. Min et al. (2010) developed an inventory model for deteriorating items under stock-dependent demand and two-level trade credit. The inventory models under two levels of trade credit policy using the viewpoint of Huang (2003) can be found in several research papers such as Feng et al. (2013), Kreng and Tan (2010), Chung (2013) and Zhou et al. (2013).

The present study investigated the inventory model especially for a manufacturer under two levels of trade credit. Here, we are taking into account the following factors:

(1) Manufactured product not only deteriorates continuously but also has a maximum lifetime;

(2) Supplier offers trade credit period of $M$ to the manufacturer while in turn manufacturer provides a trade credit period of $\mathrm{N}$ to his/her wholesaler.

(3) the production rate is finite;
(4) the supplier is willing to provide the manufacturer a full trade credit period for payments and the manufacturer offers the partial trade credit period to his/her wholesaler;

Under these conditions, we develop an inventory system as a cost minimization problem. By applying convex fractional programming results, we obtain necessary and sufficient conditions of an optimal solution. Few theorems have been developed to determine manufacturer's optimal policies. Numerical examples are given to illustrate these theorems. In addition, some managerial insights on the basis the numerical examples are also concluded.

\section{ASSUMPTIONS AND NOTATIONS}

We now formulate an economic production lot size model incorporating marketing decisions under the following assumptions and notations.

\section{Assumptions:}

1. Manufacturing system involves only single type of product which manufactured at the rate $\mathrm{P}$.

2. $\mathrm{kT}(0<\mathrm{k}<1)$ is the time upto which the manufacturing process goes on i.e. after time $\mathrm{t}=\mathrm{kT}$, the manufacturing process is discontinued. $\mathrm{T}$ is the manufacturer's cycle time.

3. All the manufactured products have certain life period after that period the worth of the product becomes zero. That period is known as lifetime of the product. When time is approaching to the maximum life $(\mathrm{m})$ of the product the deterioration rate becomes closer to 1 . We follow the same assumption as in Sarkar (2012) that the deterioration rate is

$$
\theta(t)=\frac{1}{1+m-t}, \quad 0 \leq t \leq T \leq m
$$

Here, we consider the case that the cycle time is less than or equal to $\mathrm{m}$.

4. The supplier offers the full trade credit to the manufacturer, when $\mathrm{T} \geq \mathrm{M}$, the account settled at $\mathrm{T}=\mathrm{M}$, the retailers pays off all units sold and keeps his/her profits, and starts paying for the interest charges on the items in stock with rate $I_{c}$. When $T \leq M$, the account is settled at $\mathrm{T}=\mathrm{M}$ and the retailer no need to pay any interest on the stock.

5. Credit period reduces the manufacturer's inventory holding cost, and hence a positive impact on demand. Similarly, selling price of product has also produces positive impact on the demand. So, we consider demand as a function of trade credit, advertisement and selling price.

$$
D(s, M)=a e^{b M}+d s^{-\beta} \quad \mathrm{a}, \mathrm{b}, \mathrm{d}>0
$$

Where $\mathrm{M}$ is the credit period in years offered by the supplier to manufacturer, and ' $\mathrm{s}$ ' is the selling price per unit in dollars.

6. The manufacturer just offers the partial trade credit to his/her wholesaler. Hence, the wholesaler must make a partial payment to the manufacturer when the items are sold. Then the wholesaler must pay off the remaining balance at the end of the trade credit period offered by the manufacturer. That is, the manufacturer can accumulate interest from his/her wholesaler payment with rate $\mathrm{I}_{\mathrm{e}}$. 
7. Shortages are not allowed and lead time is zero.

8. Time horizon is infinite.

\section{Notations:}

$\mathrm{h}$ : Inventory holding cost per item per year excluding interest charges

A: Setup cost per manufacturing cycle

c: The unit purchase cost per unit item

s: The unit selling price of items of good quality where $s \geq c$

$\alpha$ : Wholesaler's fraction of the total amount owed payable at the time of placing an order offered by the manufacturer $0 \leq \alpha \leq 1$

M: Manufacturer's trade credit period offered by the supplier in years

$\mathrm{N}$ : Wholesaler's trade credit period offered by the manufacturer in year

$\mathrm{I}_{\mathrm{c}}$ : The interest charged per year per $\$$ in stocks by the supplier

$\mathrm{I}_{\mathrm{e}}$ : The interest earned per \$ per year

\section{MATHEMATICAL MODELING OF MANUFACTURING SYSTEM UNDER TWO LEVEL OF TRADE CREDIT}

In this paper, we developed a manufacturer's EMQ-based inventory model under two levels of trade credit. It is assumed that the position of manufacturer in market is strong and can obtained full trade credit offered by the supplier and the manufacturer just offered partial trade credit to his wholesaler.

A production process starts at $\mathrm{t}=0$ at the rate $\mathrm{P}$ and continues upto $\mathrm{t}=\mathrm{kT}$ where the inventory level reaches the maximum level. During this period, inventory level rises due to production and decline due to demand and deterioration. At $\mathrm{t}=\mathrm{kT}$ production process stop and afterward inventory level declines due demand and deterioration only. Inventory level reaches to zero at $\mathrm{t}=\mathrm{T}$. This process continues as the planning horizon in infinite. The graphical representation of this inventory system is clearly depicted in Fig.1. The transition of inventory during the planning horizon can be represented by the following differential equation:

$$
\frac{d I_{1}(t)}{d t}+\frac{1}{1+m-t} I(t)=P-D(s, M), \quad 0 \leq t \leq \mathrm{kT}
$$

With the initial conditions $I_{1}(0)=0$.



Fig.1 Pictorial Representation of Inventory Level of Manufacturer
The solution of the above equation with the initial condition $I_{1}(0)=0$ is

$$
I_{1}(t)=(1+m-t)(P-D(s, M)) \log \left(\frac{1+m}{(1+m-t)}\right)
$$

$0 \leq t \leq \mathrm{kT}$

In the interval $(\mathrm{kT}, \mathrm{T}]$, the inventory is decreases due to demand and deterioration. Hence, the change in the inventory level can be represented by the following differential equations:

$$
\frac{d I_{2}(t)}{d t}+p(t) I(t)=-D(s, M), \quad \mathrm{kT} \leq t \leq T
$$

With the boundary conditions $I_{2}(\mathrm{~T})=0$.

The solution of the above equation with the boundary condition $I_{2}(\mathrm{~T})=0$ is

$$
I_{2}(t)=D(s, M)(1+m-t) \log \left(\frac{1+m-t}{(1+m-T)}\right)
$$

Now, we can evaluate the total cost associated with the manufacturer which is comprised of the annual setup cost, annual holding cost, annual interest payable, annual interest earned.

Annual setup cost $=\mathrm{A} / \mathrm{T}$

Annual holding cost (excluding interest charges) = $\frac{h}{T}\left[\int_{0}^{k T} I_{1}(t) d t+\int_{k T}^{T} I_{2}(t) d t\right]$

$=\frac{h}{T}\left[(P-D(s, M)) \int_{0}^{k T_{1}}(1+m-t) \log \left(\frac{1+m}{(1+m-t)}\right) d t+\right.$

$\left.D(s, M) \int_{k T}^{T}(1+m-t) \log \left(\frac{1+m-t}{(1+m-T)}\right) d t\right]$

$=$

$\frac{h}{T}\left[(P-D(s, M))\left(\frac{(1+m)^{2}}{4}-\right.\right.$

$\left.\frac{(1+m-k T)^{2}}{4}\left(1+2 \log \left(\frac{1+m}{1+m-k T}\right)\right)\right)+$

$\left.D(s, M)\left(\frac{(1+m-T)^{2}}{4}+\frac{(1+m-k T)^{2}}{4}\left(2 \log \left(\frac{1+m-k T}{1+m-T}\right)-1\right)\right)\right]$

The objective of the manufacturer is to determine his/her optimal cycle time $\mathrm{T}^{*}$ such that his/her total inventory cost is minimum. For the derivation of the manufacturer's annual total inventory cost, the up-stream and the down-stream trade credits should be taken into consideration. From the values of $\mathrm{N}$ and $\mathrm{M}$, there are two possible cases:

Case-1: $\mathrm{M}>\mathrm{N} \quad$ Case- $2: \mathrm{N} \geq \mathrm{M}$

Now, we discuss these two cases separately one by one.

\section{Case-1: $M>N$}

On the bases of the values of $\mathrm{M}, \mathrm{T}, \mathrm{T}+\mathrm{N}$ (the time at which the manufacturer receives the payment from the last wholesaler), three sub-cases can occur.

\section{Sub-Case-1.1: $M \leq T$}

In this sub-case, the manufacturer accumulates revenue and earns interest:

(i). from the portion of instant payment starting time 0 through $\mathrm{M}$ and 
(ii). from the portion of delayed payment starting time $\mathrm{N}$ through $\mathrm{M}$.

Therefore,

The interest earned per cycle $=\mathrm{I}_{\mathrm{e}} *(\operatorname{Ar}(\Delta(\mathrm{OMA}))+$ $\operatorname{Ar}(\Delta(\mathrm{NMA}))$ as shown in Fig.2).

Therefore, annual interest earned is given by

$\frac{s I_{e} D(s, M)}{2 T}\left(\alpha M^{2}+(1-\alpha)(M-N)^{2}\right)$

On the other hand, the manufacturer grants its wholesaler a trade credit of $\mathrm{N}$ periods, and receives the money from its wholesaler from time $\mathrm{N}$ through $\mathrm{T}+\mathrm{N}$. Thus, at time $\mathrm{M}$ the manufacturer receives $\alpha s D(s, M) M$ dollars from the instant payment and $(1-\alpha) s D(s, M)(M-N)$ dollars from delayed payment, and pays its supplier $\alpha c D(s, M) M+(1-$ $\alpha) c D(s, M)(M-N)$ dollars. The manufacturer must finance

(i). all items sold after $\mathrm{M}$ for the portion of instant payment, and

(ii). all items sold after $\mathrm{M}-\mathrm{N}$ for the portion of delayed payment at an interest charged $\mathrm{I}_{\mathrm{c}}$ per dollar per year.

As a result, the interest payable per cycle $=\mathrm{cI}_{\mathrm{c}} *(\operatorname{Ar}(\Delta(\mathrm{ABC}))+$ $\operatorname{Ar}\left(\Delta\left(\mathrm{A}^{`} \mathrm{~B}^{`} \mathrm{C}^{\prime}\right)\right)$ as shown in Fig.2.

Revenue
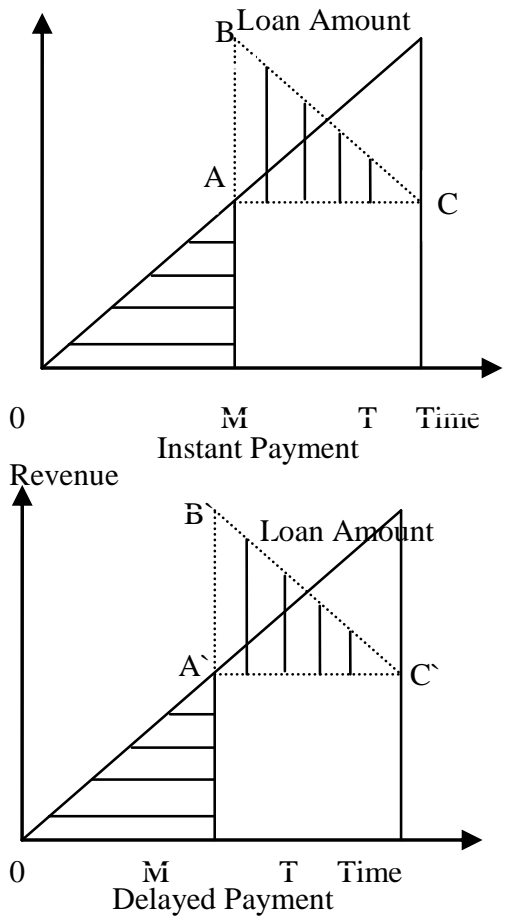

Fig. $2 \mathrm{M}>\mathrm{N}$ and $\mathrm{M} \leq \mathrm{T}$

Therefore, the annual interest payable is given by

$\frac{c I_{C} D(s, M)}{2 T}\left(\alpha(T-M)^{2}+(1-\alpha)(T+N-M)^{2}\right)$

The manufacturer's annual total relevant cost is

$T R C_{1.1}(T)=\frac{\mathrm{A}}{\mathrm{T}}+\frac{h}{T}\left[(P-D(M, s))\left(\frac{(1+m)^{2}}{4}-\frac{\left(1+m-T_{1}\right)^{2}}{4}(1+\right.\right.$

$\left.\left.2 \log \left(\frac{1+m}{1+m-T_{1}}\right)\right)\right)+$
$\left.D(M, s)\left(\frac{(1+m-T)^{2}}{4}+\frac{\left(1+m-T_{1}\right)^{2}}{4}\left(2 \log \left(\frac{1+m-T_{1}}{1+m-T}\right)-1\right)\right)\right]+$
$\frac{c I_{c} D(s, M)}{2 T}\left(\alpha(T-M)^{2}+(1-\alpha)(T+N-M)^{2}\right)-$
$\frac{s I_{e} D(s, M)}{2 T}\left(\alpha M^{2}+(1-\alpha)(M-N)^{2}\right)$

Sub-.Case-1.2: $T \leq M \leq T+N$

In this case, manufacturer accumulates revenue and there are two different accounts from where he/she can earn interest.

(i). the portion of immediate payment starting time 0 through $\mathrm{M}$, and

(ii). the portion of delayed payment starting from $\mathrm{N}$ through M.

Hence, the manufacturer's annual interest earned as shown in Fig. 3 as

$\frac{s I_{e} D(s, M)}{2 T}\left(\alpha T^{2}+2 \alpha T(M-T)+(1-\alpha)(M-N)^{2}\right)$

The manufacturer receives all instant payment by time $\mathrm{T}(\leq \mathrm{M})$ so that there is no interest payable for the portion of instant payment. However, the manufacturer must finance all items sold during time interval $[\mathrm{M}-\mathrm{N}, \mathrm{T}]$. Therefore, the annual interest payable is

$\frac{c I_{c} D(s, M)}{2 T}(1-\alpha)(T+N-M)^{2}$

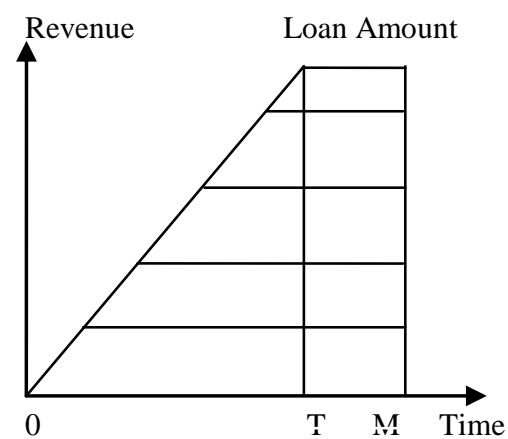

Instant Payment

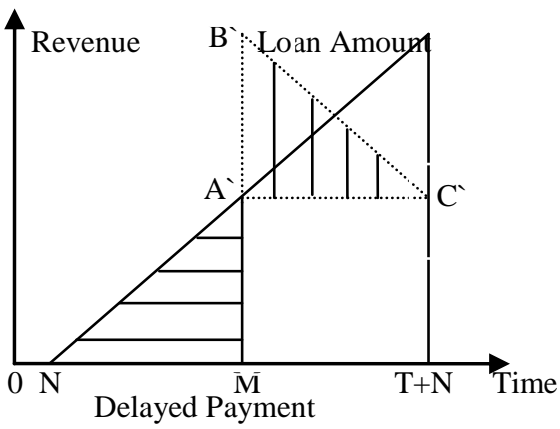

Fig. $3 \mathrm{M}>\mathrm{N}$ and $\mathrm{T} \leq \mathrm{M} \leq \mathrm{T}+\mathrm{N}$

The manufacturer's annual total relevant cost by

$T R C_{1.2}(T)=\frac{\mathrm{A}}{\mathrm{T}}+\frac{h}{T}\left[(P-D(s, M))\left(\frac{(1+m)^{2}}{4}-\frac{\left(1+m-T_{1}\right)^{2}}{4}(1+\right.\right.$

$\left.\left.2 \log \left(\frac{1+m}{1+m-T_{1}}\right)\right)\right)+$

$\left.D(s, M)\left(\frac{(1+m-T)^{2}}{4}+\frac{\left(1+m-T_{1}\right)^{2}}{4}\left(2 \log \left(\frac{1+m-T_{1}}{1+m-T}\right)-1\right)\right)\right]+$

$\frac{c I_{C} D(s, M)}{2 T}(1-\alpha)(T+N-M)^{2}-\frac{s I_{e} D(s, M)}{2 T}\left(\alpha T^{2}+\right.$ 
$\left.2 \alpha T(M-T)+(1-\alpha)(M-N)^{2}\right)$

\section{Sub-Case-1.3: $\mathbf{T}+\mathbf{N} \leq \mathbf{M}$}

The manufacturer receives the total revenue before the trade credit period $\mathrm{M}$, and hence there is no interest payable.

From Fig.4, the annual interest earned is

$\frac{s I_{e} D(s, M)}{2 T}\left(\alpha T^{2}+2 \alpha T(M-T)+(1-\alpha) T^{2}+2(1-\right.$

a)T $(M-T-N))$

$=\frac{s I_{e} D(s, M)}{2}(2 M-T-2(1-\alpha) N)$

The manufacturer's annual total relevant cost by

$T R C_{1.3}(T)=\frac{\mathrm{A}}{\mathrm{T}}+\frac{h}{T}\left[(P-D(s, M))\left(\frac{(1+m)^{2}}{4}-\frac{\left(1+m-T_{1}\right)^{2}}{4}(1+\right.\right.$ $\left.\left.2 \log \left(\frac{1+m}{1+m-T_{1}}\right)\right)\right)+$

$\left.D(s, M)\left(\frac{(1+m-T)^{2}}{4}+\frac{\left(1+m-T_{1}\right)^{2}}{4}\left(2 \log \left(\frac{1+m-T_{1}}{1+m-T}\right)-1\right)\right)\right]-$

$\frac{s I_{e} D(s, M)}{2}(2 M-T-2(1-\alpha) N)$

Revenue

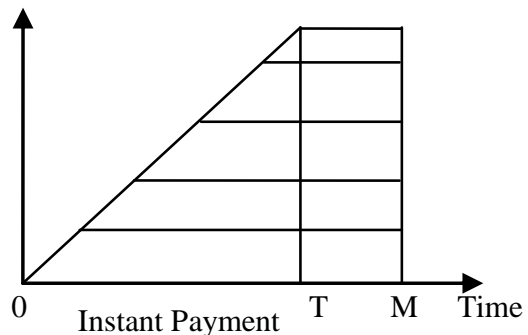

Re'venue

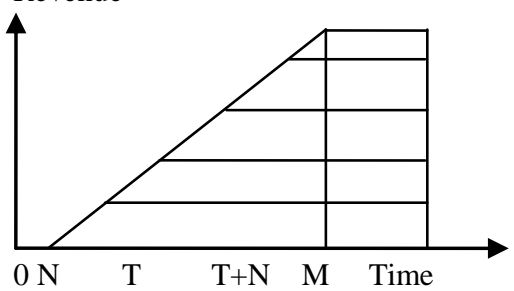

Delayed Payment

Fig.4 $M>N$ and $T+N \leq M$

The manufacturer's annual total relevant cost is given by

$T R C_{1}(T)=\left\{\begin{array}{l}T R C_{1.1}(T) \\ T R C_{1.2}(T) \\ T R C_{1.3}(T)\end{array}\right.$

if $M \leq T$

if $T \leq M \leq T+N$

if $T+N \leq M$

Hence, $T R C_{1}(T)$ is continuous in $\mathrm{T}$, and has the following properties

$$
\begin{gathered}
T R C_{1.1}(M)=T R C_{1.2}(M) \\
T R C_{1.2}(M-N)=T R C_{1.3}(M-N)
\end{gathered}
$$

\section{Case-2: $M \leq N$}

Now, on the bases of the values of $\mathrm{M}$ and $\mathrm{T}$, the following two sub-cases can occur: (i) $\mathrm{M} \leq \mathrm{T}$ and (ii) $\mathrm{M} \geq \mathrm{T}$. Now, we discuss them in length.

\section{Sub-Case-2.1: $M \leq T$}

From Fig.5, the annual interest earned from the instant payment is

$\frac{s I_{e} D(s, M)}{2 T}\left(\alpha M^{2}\right)$

In this sub-case, for immediate payment the manufacturer must finance $\alpha c D(s, M)(T-M)$ at time $\mathrm{M}$, and pay off the loan at time T. The manufacturer must finance (1$\alpha) c D(s, M) T$ for delayed payment at time $\mathrm{M}$, and pay off the loan at time $\mathrm{T}+\mathrm{N}$. Therefore, the annual interest payable is

$\frac{c I_{c} D(s, M)}{2 T}\left(\alpha(T-M)^{2}+(1-\alpha) T(T+2(N-M))\right.$

\section{Revenue}
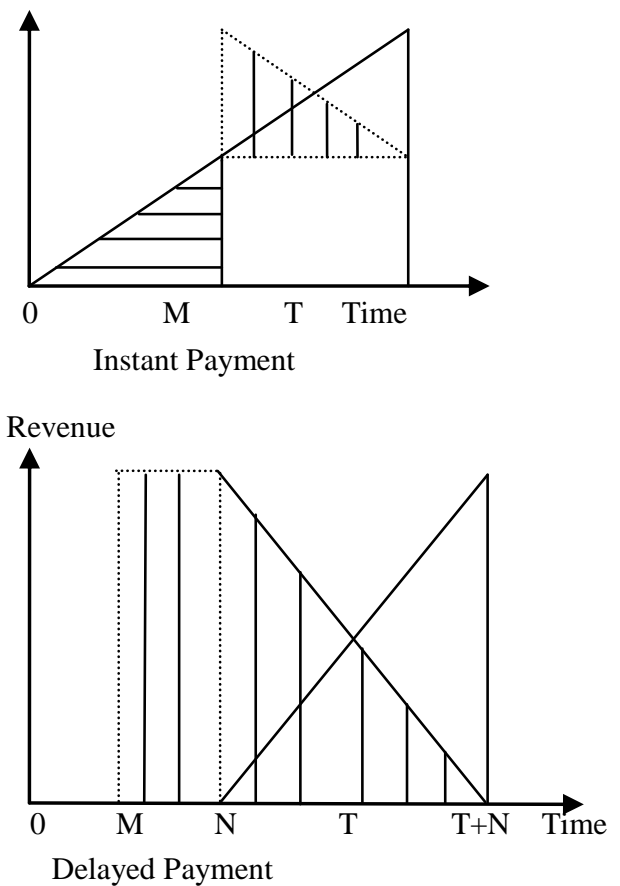

Fig.5 $M \leq N$ and $M \leq T$

The annual total relevant cost of the manufacturer is

$T R C_{2.1}(T)=\frac{\mathrm{A}}{\mathrm{T}}+\frac{h}{T}\left[(P-D(s, M))\left(\frac{(1+m)^{2}}{4}-\frac{\left(1+m-T_{1}\right)^{2}}{4}(1+\right.\right.$ $\left.\left.2 \log \left(\frac{1+m}{1+m-T_{1}}\right)\right)\right)+$

$\left.D(s, M)\left(\frac{(1+m-T)^{2}}{4}+\frac{\left(1+m-T_{1}\right)^{2}}{4}\left(2 \log \left(\frac{1+m-T_{1}}{1+m-T}\right)-1\right)\right)\right]+$ $\frac{c I_{c} D(s, M)}{2 T}\left(\alpha(T-M)^{2}+(1-\alpha) T(T+2(N-M))-\right.$ $\frac{s I_{e} D(s, M)}{2 T}\left(\alpha M^{2}\right)$

\section{Sub-Case-2.2: $M \geq T$}

From Fig.6, the annual interest earned from the instant payment is

$\frac{s \alpha I_{e} D(s, M)}{2}(T+2(M-T))$

In this case, there is no interest payable for immediate payment. However, the manufacturer must finance (1$\alpha) c D(s, M) T$ for delayed payment at time $\mathbf{M}$, and pay off the loan at time $\mathrm{T}+\mathrm{N}$. Therefore, the annual interest payable is 
$\frac{c \alpha I_{c} D(s, M)}{2}(1-\alpha)(T+2(N-M))$

Revenue

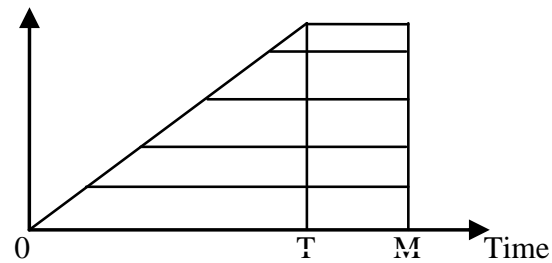

Revenue Instant Payment

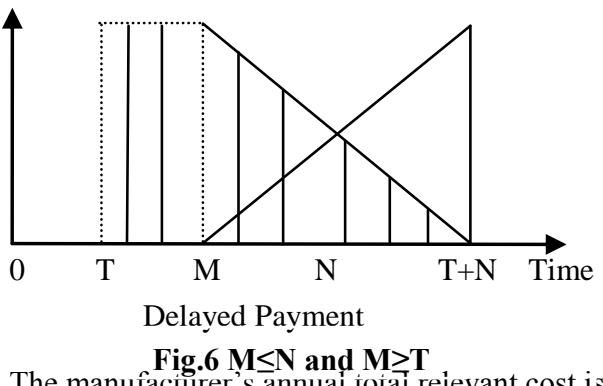

The manufaciurer's annual iotal relevant cost is

$T R C_{2.2}(T)=\frac{\mathrm{A}}{\mathrm{T}}+\frac{h}{T}\left[(P-D(s, M))\left(\frac{(1+m)^{2}}{4}-\frac{\left(1+m-T_{1}\right)^{2}}{4}(1+\right.\right.$

$\left.\left.2 \log \left(\frac{1+m}{1+m-T_{1}}\right)\right)\right)+$

$\left.D(s, M)\left(\frac{(1+m-T)^{2}}{4}+\frac{\left(1+m-T_{1}\right)^{2}}{4}\left(2 \log \left(\frac{1+m-T_{1}}{1+m-T}\right)-1\right)\right)\right]+$

$\frac{c \alpha I_{c} D(s, M)}{2}(1-\alpha)(T+2(N-M))$

$(T+2(M-T))-\frac{s \alpha I_{e} D(s, M)}{2}(T+2(M-T))$

The manufacturer's annual total cost is

$T R C_{2}(T)= \begin{cases}T R C_{2.1}(T) & \text { if } M \leq T \\ T R C_{2.1}(T) & \text { if } M \geq T\end{cases}$

It is clear that $T R C_{2}(T)$ is continuous in $\mathrm{T}$, and has the following properties

$$
T R C_{2.1}(M)=T R C_{2.2}(M)
$$

Now, we have to determine the optimal cycle $T^{*}$ for both cases of $\mathrm{N}<\mathrm{M}$ and $\mathrm{N} \geq \mathrm{M}$.

\section{DETERMINATION OF THE OPTIMAL CYCLE}

In this section, the necessary and sufficient conditions for the determination of the optimal solution, say $\left(\mathrm{T}^{*}, \mathrm{TRC}^{*}(\mathrm{~T})\right)$ are presented here for the case $\mathrm{N}<\mathrm{M}$ and $\mathrm{N} \geq \mathrm{M}$.

Intermediate Value Theorem: Let $\mathrm{g}(\mathrm{x})$ be a continuous function on $[a, b]$ and $g(a) g(b)<0$, then there exists a number $c \in(a, b)$ such that $\mathrm{g}(\mathrm{c})=0$.

Property-1: For a function $g: S \rightarrow R_{1}$ defined by $\mathrm{g}(\mathrm{x})=\mathrm{f}(\mathrm{x}) / \mathrm{h}(\mathrm{x})$ where $\mathrm{f}: \mathrm{S} \rightarrow \mathrm{R}_{1}$, and $\mathrm{S}$ is a non-empty convex set in $E_{n}$. The following discuss convexity and concavity functions:

(a). $\mathrm{f}$ is convex on $\mathrm{S}$, and $\mathrm{f}(\mathrm{x}) \geq 0$ for each $x \in S$. (b). $\mathrm{h}$ is concave on $\mathrm{S}$, and $\mathrm{h}(\mathrm{x}) \geq 0$ for each $x \in S$, and

(c). Both $\mathrm{f}$ and $\mathrm{h}$ are differentiable.

The $g(x)$ is convex if $f(x)$ is convex and $h(x)$ is concave.

\subsection{Determination of Optimal Cycle Time for the Case of $\mathrm{N}<\mathrm{M}$}

By applying the above mentioned results, we separately minimize each of $\operatorname{TRC}_{1 . i}(\mathrm{~T})$ for $\mathrm{i}=1,2,3$ and obtain the following theoretical results.

\section{Theorem-1:}

1. $T R C_{1.1}(T)$ is a strictly pseudo-convex function in $\mathrm{T}$, and hence there exists a unique minimum solution $T_{a}^{*}$.

2. If $\mathrm{M} \leq T_{a}^{*}$ then $T R C_{1.1}(T)$ subjected to $\mathrm{M} \leq \mathrm{T}$ is minimized at $T_{a}^{*}$.

3. If $\mathrm{M} \geq T_{a}^{*}$ then (T) subjected to $\mathrm{M} \leq \mathrm{T}$ is minimized at $M$.

Proof: Let

$\mathrm{f}(\mathrm{T})=\mathrm{A}+\mathrm{h}\left[(P-D(s, M))\left(\frac{(1+m)^{2}}{4}-\frac{\left(1+m-T_{1}\right)^{2}}{4}(1+\right.\right.$

$\left.\left.2 \log \left(\frac{1+m}{1+m-T_{1}}\right)\right)\right)+$

$\left.D(s, M)\left(\frac{(1+m-T)^{2}}{4}+\frac{\left(1+m-T_{1}\right)^{2}}{4}\left(2 \log \left(\frac{1+m-T_{1}}{1+m-T}\right)-1\right)\right)\right]+$

$\frac{c I_{c} D(s, M)}{2}\left(\alpha(T-M)^{2}+(1-\alpha)(T+N-M)^{2}\right)-$

$\frac{s I_{e} D(s, M)}{2}\left(\alpha M^{2}+(1-\alpha)(M-N)^{2}\right) \geq 0$ for $T>0$

and

$\mathrm{h}(\mathrm{T})=\mathrm{T}>0$

Taking first and second derivative of $\mathrm{f}(\mathrm{T})$, we get

$\frac{d f(T)}{d T}=$

$\mathrm{h}\left[(P-D(s, M))\left(\frac{k(1+m-k T)}{2}\left(1+2 \log \left(\frac{1+m}{1+m-k T}\right)\right)-\right.\right.$ $\left.\frac{k(1+m-k T)}{2}\right)+$

$D(s, M)\left(-\frac{(1+m-T)}{2}-\frac{k(1+m-k T)}{2}\left(2 \log \left(\frac{1+m-k T}{1+m-T}\right)-1\right)+\right.$

$\left.\left.\frac{(1+m-k T)^{2}}{4}\left(-\frac{2 k}{(1+m-k T)}+\frac{2}{(1+m-T)}\right)\right)\right]+c I_{c} D(s, M)((T-$

$M)+(1-\alpha) N)$

$\frac{d^{2} f(T)}{d T^{2}}=\mathrm{h}\left[(P-D(s, M))\left(-\frac{k^{2}}{2}\left(1+2 \log \left(\frac{1+m}{1+m-k T}\right)\right)+\right.\right.$

$\left.\frac{3 k^{2}}{2}\right)+$

$D(s, M)\left(\frac{1}{2}+\frac{k^{2}}{2}\left(2 \log \left(\frac{1+m-k T}{1+m-T}\right)-1\right)-k(1+m-\right.$

$k T)\left(-\frac{2 k}{(1+m-k T)}+\frac{2}{(1+m-T)}\right)+\frac{(1+m-k T)^{2}}{2}\left(-\frac{2 k^{2}}{(1+m-k T)^{2}}+\right.$

$\left.\left.\left.\frac{2}{(1+m-T)^{2}}\right)\right)\right]+c I_{c} D(s, M)>0$

Therefore, $T R C_{1.1}(T)=g(T) / h(T)$ is a strictly pseudo convex function in $\mathrm{T}$, which completes the proof of part (1).

Part (2) and (3) are the direct consequences of part (1). 
To find $T_{a}^{*}$, we set $\frac{d T R C_{1.1}(T)}{d T}=0$

$\mathrm{hT}\left[(P-D(s, M))\left(\frac{k(1+m-k T)}{2}\left(1+2 \log \left(\frac{1+m}{1+m-k T}\right)\right)-\right.\right.$ $\left.\frac{k(1+m-k T)}{2}\right)+$

$D(s, M)\left(-\frac{(1+m-T)}{2}-\frac{k(1+m-k T)}{2}\left(2 \log \left(\frac{1+m-k T}{1+m-T}\right)-1\right)+\right.$

$\left.\left.\frac{(1+m-k T)^{2}}{4}\left(-\frac{2 k}{(1+m-k T)}+\frac{2}{(1+m-T)}\right)\right)\right]-\mathrm{h}[(P-$

$D(s, M))\left(\frac{k(1+m-k T)}{2}\left(1+2 \log \left(\frac{1+m}{1+m-k T}\right)\right)-\frac{k(1+m-k T)}{2}\right)+$

$D(s, M)\left(-\frac{(1+m-T)}{2}-\frac{k(1+m-k T)}{2}\left(2 \log \left(\frac{1+m-k T}{1+m-T}\right)-1\right)+\right.$

$\left.\left.\frac{(1+m-k T)^{2}}{4}\left(-\frac{2 k}{(1+m-k T)}+\frac{2}{(1+m-T)}\right)\right)\right]+$

$\frac{D(s, M)\left[\alpha M^{2}+(1-\alpha)(M-N)^{2}\right]\left[s I_{e}-c I_{c}\right]}{2}+\frac{c I_{C} D(s, M) T^{2}}{2}-A(n)=0$

\section{Theorem-2:}

1. $T R C_{1.2}(T)$ is a strictly pseudo-convex function in $\mathrm{T}$, and hence there exists a unique minimum solution $T_{b}^{*}$.

2. If $\mathrm{M}-\mathrm{N} \leq T_{b}^{*} \leq M$ then $T R C_{1.2}(T)$ subjected to $\mathrm{T} \leq \mathrm{M} \leq \mathrm{T}+\mathrm{N}$ is minimized at $T_{b}^{*}$.

3. If $T_{b}^{*} \leq M-N$ then $T R C_{1.2}(T)$ subjected to $\mathrm{T} \leq \mathrm{M} \leq \mathrm{T}+\mathrm{N}$ is minimized at $M-N$.

4. If $T_{b}^{*} \geq \mathrm{M}$ then $T R C_{1.2}(T)$ subjected to $\mathrm{T} \leq \mathrm{M} \leq \mathrm{T}+\mathrm{N}$ is minimized at $M$.

Proof: Let

$\mathrm{f}(\mathrm{T})=\mathrm{A}+\mathrm{h}\left[(P-D(s, M))\left(\frac{(1+m)^{2}}{4}-\frac{\left(1+m-T_{1}\right)^{2}}{4}(1+\right.\right.$

$\left.\left.2 \log \left(\frac{1+m}{1+m-T_{1}}\right)\right)\right)+$

$\left.D(s, M)\left(\frac{(1+m-T)^{2}}{4}+\frac{\left(1+m-T_{1}\right)^{2}}{4}\left(2 \log \left(\frac{1+m-T_{1}}{1+m-T}\right)-1\right)\right)\right]+$ $\frac{c I_{C} D(s, M)}{2}(1-\alpha)(T+N-M)^{2}-\frac{s I_{e} D(s, M)}{2}\left(\alpha T^{2}+\right.$

$\left.2 \alpha T(M-T)+(1-\alpha)(M-N)^{2}\right) \geq 0$ for $T>0$

and

$\mathrm{h}(\mathrm{T})=\mathrm{T}>0$

Taking first and second derivative of $\mathrm{g}(\mathrm{T})$, we get

$\frac{d f(T)}{d T}=$

$\mathrm{h}\left[(P-D(s, M))\left(\frac{k(1+m-k T)}{2}\left(1+2 \log \left(\frac{1+m}{1+m-k T}\right)\right)-\right.\right.$

$\left.\frac{k(1+m-k T)}{2}\right)+$

$D(s, M)\left(-\frac{(1+m-T)}{2}-\frac{k(1+m-k T)}{2}\left(2 \log \left(\frac{1+m-k T}{1+m-T}\right)-1\right)+\right.$

$\left.\left.\frac{(1+m-k T)^{2}}{4}\left(-\frac{2 k}{(1+m-k T)}+\frac{2}{(1+m-T)}\right)\right)\right]+c I_{c} D(s, M)(1-$

$\alpha)(T-M+N)-s I_{e} D(s, M) \alpha(M-T)$

$\frac{d^{2} f(T)}{d T^{2}}=\mathrm{h}\left[(P-D(s, M))\left(-\frac{k^{2}}{2}\left(1+2 \log \left(\frac{1+m}{1+m-k T}\right)\right)+\right.\right.$ $\left.\frac{3 k^{2}}{2}\right)+$
$D(s, M)\left(\frac{1}{2}+\frac{k^{2}}{2}\left(2 \log \left(\frac{1+m-k T}{1+m-T}\right)-1\right)-k(1+m-\right.$

$k T)\left(-\frac{2 k}{(1+m-k T)}+\frac{2}{(1+m-T)}\right)+\frac{(1+m-k T)^{2}}{2}\left(-\frac{2 k^{2}}{(1+m-k T)^{2}}+\right.$

$\left.\left.\left.\frac{2}{(1+m-T)^{2}}\right)\right)\right]+D(s, M)\left(c(1-\alpha) I_{c}+\alpha s I_{e}\right)>0$

Therefore, $T R C_{1.2}(T)=g(T) / h(T)$ is a strictly pseudo convex function in $\mathrm{T}$, which completes the proof of part (1).

Part (2), (3) and (4) are the direct consequences of part (1).

To find $T_{b}^{*}$, we set $\frac{d T R C_{1.2}(T)}{d T}=0$

$\mathrm{hT}\left[(P-D(s, M))\left(\frac{k(1+m-k T)}{2}\left(1+2 \log \left(\frac{1+m}{1+m-k T}\right)\right)-\right.\right.$ $\left.\frac{k(1+m-k T)}{2}\right)+$

$D(s, M)\left(-\frac{(1+m-T)}{2}-\frac{k(1+m-k T)}{2}\left(2 \log \left(\frac{1+m-k T}{1+m-T}\right)-1\right)+\right.$

$\left.\left.\frac{(1+m-k T)^{2}}{4}\left(-\frac{2 k}{(1+m-k T)}+\frac{2}{(1+m-T)}\right)\right)\right]-\mathrm{h}[(P-$

$D(s, M))\left(\frac{k(1+m-k T)}{2}\left(1+2 \log \left(\frac{1+m}{1+m-k T}\right)\right)-\frac{k(1+m-k T)}{2}\right)+$

$D(s, M)\left(-\frac{(1+m-T)}{2}-\frac{k(1+m-k T)}{2}\left(2 \log \left(\frac{1+m-k T}{1+m-T}\right)-1\right)+\right.$

$\left.\left.\frac{(1+m-k T)^{2}}{4}\left(-\frac{2 k}{(1+m-k T)}+\frac{2}{(1+m-T)}\right)\right)\right]+$

$\frac{D(s, M)(1-\alpha)(M-N)^{2}\left[s I_{e}-c I_{c}\right]}{2}+\frac{D(s, M) T^{2}\left[\alpha s I_{e}+(1-\alpha) c I_{c}\right]}{2}-A(n)=0$

Theorem-3:

1. $T R C_{1.3}(T)$ is a strictly pseudo-convex function in $\mathrm{T}$, and hence there exists a unique minimum solution $T_{c}^{*}$.

2. If $T_{c}^{*} \leq M-N$ then $T R C_{1.3}(T)$ subjected to $\mathrm{T}+\mathrm{N} \leq \mathrm{M}$ is minimized at $T_{c}^{*}$.

3. If $T_{c}^{*} \geq M-N$ then $T R C_{13}(T)$ subjected to $\mathrm{T}+\mathrm{N} \leq \mathrm{M}$ is minimized at $M-N$.

Proof: Let

$\mathrm{f}(\mathrm{T})=\mathrm{A}+\mathrm{h}\left[(P-D(s, M))\left(\frac{(1+m)^{2}}{4}-\frac{\left(1+m-T_{1}\right)^{2}}{4}(1+\right.\right.$

$\left.\left.2 \log \left(\frac{1+m}{1+m-T_{1}}\right)\right)\right)+$

$\left.D(s, M)\left(\frac{(1+m-T)^{2}}{4}+\frac{\left(1+m-T_{1}\right)^{2}}{4}\left(2 \log \left(\frac{1+m-T_{1}}{1+m-T}\right)-1\right)\right)\right]-$ $\frac{s I_{e} D(s, M)}{2}\left(2 M T-T^{2}-2(1-\alpha) N T\right) \geq 0$ for $T>0$

and

$\mathrm{h}(\mathrm{T})=\mathrm{T}>0$

Taking first and second derivative of $\mathrm{g}(\mathrm{T})$, we get

$\frac{d f(T)}{d T}=$

$\mathrm{h}\left[(P-D(s, M))\left(\frac{k(1+m-k T)}{2}\left(1+2 \log \left(\frac{1+m}{1+m-k T}\right)\right)-\right.\right.$ $\left.\frac{k(1+m-k T)}{2}\right)+$ 


$$
\begin{aligned}
& D(s, M)\left(-\frac{(1+m-T)}{2}-\frac{k(1+m-k T)}{2}\left(2 \log \left(\frac{1+m-k T}{1+m-T}\right)-1\right)+\right. \\
& \left.\left.\frac{(1+m-k T)^{2}}{4}\left(-\frac{2 k}{(1+m-k T)}+\frac{2}{(1+m-T)}\right)\right)\right]-s I_{e} D(s, M)(M-T- \\
& (1-\alpha) N) \\
& \frac{d^{2} f(T)}{d T^{2}}=\mathrm{h}\left[( P - D ( s , M ) ) \left(-\frac{k^{2}}{2}\left(1+2 \log \left(\frac{1+m}{1+m-k T}\right)\right)+\right.\right. \\
& \left.\frac{3 k^{2}}{2}\right)+ \\
& D(s, M)\left(\frac{1}{2}+\frac{k^{2}}{2}\left(2 \log \left(\frac{1+m-k T}{1+m-T}\right)-1\right)-k(1+m-\right. \\
& k T)\left(-\frac{2 k}{(1+m-k T)}+\frac{2}{(1+m-T)}\right)+\frac{(1+m-k T)^{2}}{2}\left(-\frac{2 k^{2}}{(1+m-k T)^{2}}+\right. \\
& \left.\left.\left.\frac{2}{(1+m-T)^{2}}\right)\right)\right]+s I_{e} D(s, M)>0
\end{aligned}
$$

Therefore, $T R C_{1.3}(T)=g(T) / h(T)$ is a strictly pseudo convex function in $\mathrm{T}$, which completes the proof of part (1).

Part (2), and (3) are the direct consequences of part (1).

To find $T_{c}^{*}$, we set $\frac{d T R C_{1.3}(T)}{d T}=0$

$\mathrm{hT}\left[(P-D(s, M))\left(\frac{k(1+m-k T)}{2}\left(1+2 \log \left(\frac{1+m}{1+m-k T}\right)\right)-\right.\right.$ $\left.\frac{k(1+m-k T)}{2}\right)+$

$$
\begin{aligned}
& D(s, M)\left(-\frac{(1+m-T)}{2}-\frac{k(1+m-k T)}{2}\left(2 \log \left(\frac{1+m-k T}{1+m-T}\right)-1\right)+\right. \\
& \left.\left.\frac{(1+m-k T)^{2}}{4}\left(-\frac{2 k}{(1+m-k T)}+\frac{2}{(1+m-T)}\right)\right)\right]-\mathrm{h}[(P- \\
& D(s, M))\left(\frac{k(1+m-k T)}{2}\left(1+2 \log \left(\frac{1+m}{1+m-k T}\right)\right)-\frac{k(1+m-k T)}{2}\right)+ \\
& D(s, M)\left(-\frac{(1+m-T)}{2}-\frac{k(1+m-k T)}{2}\left(2 \log \left(\frac{1+m-k T}{1+m-T}\right)-1\right)+\right. \\
& \left.\left.\frac{(1+m-k T)^{2}}{4}\left(-\frac{2 k}{(1+m-k T)}+\frac{2}{(1+m-T)}\right)\right)\right]+\frac{S I_{e} D(s, M) T^{2}}{2}-A=0
\end{aligned}
$$

Lemma-1: Show that $\Delta_{1}<\Delta_{2}$ where

$\Delta_{1}=\mathrm{hT}\left[(P-D(s, M))\left(\frac{k(1+m-k T)}{2}\left(1+2 \log \left(\frac{1+m}{1+m-k T}\right)\right)-\right.\right.$ $\left.\frac{k(1+m-k T)}{2}\right)+$

$D(s, M)\left(-\frac{(1+m-T)}{2}-\frac{k(1+m-k T)}{2}\left(2 \log \left(\frac{1+m-k T}{1+m-T}\right)-1\right)+\right.$

$\left.\left.\frac{(1+m-k T)^{2}}{4}\left(-\frac{2 k}{(1+m-k T)}+\frac{2}{(1+m-T)}\right)\right)\right]-\mathrm{h}[(P-$

$D(s, M))\left(\frac{k(1+m-k T)}{2}\left(1+2 \log \left(\frac{1+m}{1+m-k T}\right)\right)-\frac{k(1+m-k T)}{2}\right)+$

$D(s, M)\left(-\frac{(1+m-T)}{2}-\frac{k(1+m-k T)}{2}\left(2 \log \left(\frac{1+m-k T}{1+m-T}\right)-1\right)+\right.$

$\left.\left.\frac{(1+m-k T)^{2}}{4}\left(-\frac{2 k}{(1+m-k T)}+\frac{2}{(1+m-T)}\right)\right)\right]+\frac{s I_{e} D(s, M)(M-N)^{2}}{2}-A$

And

$\Delta_{2}=\mathrm{hT}\left[(P-D(s, M))\left(\frac{k(1+m-k T)}{2}\left(1+2 \log \left(\frac{1+m}{1+m-k T}\right)\right)-\right.\right.$ $\left.\frac{k(1+m-k T)}{2}\right)+$

$$
\begin{aligned}
& D(s, M)\left(-\frac{(1+m-T)}{2}-\frac{k(1+m-k T)}{2}\left(2 \log \left(\frac{1+m-k T}{1+m-T}\right)-1\right)+\right. \\
& \left.\left.\frac{(1+m-k T)^{2}}{4}\left(-\frac{2 k}{(1+m-k T)}+\frac{2}{(1+m-T)}\right)\right)\right]-\mathrm{h}[(P- \\
& D(s, M))\left(\frac{k(1+m-k T)}{2}\left(1+2 \log \left(\frac{1+m}{1+m-k T}\right)\right)-\frac{k(1+m-k T)}{2}\right)+ \\
& D(s, M)\left(-\frac{(1+m-T)}{2}-\frac{k(1+m-k T)}{2}\left(2 \log \left(\frac{1+m-k T}{1+m-T}\right)-1\right)+\right. \\
& \left.\left.\frac{(1+m-k T)^{2}}{4}\left(-\frac{2 k}{(1+m-k T)}+\frac{2}{(1+m-T)}\right)\right)\right]+ \\
& \frac{D(s, M)\left[\alpha M^{2}+(1-\alpha)(M-N)^{2}\right]\left[s I_{e}-c I_{c}\right]}{2}+\frac{c I_{c} D(s, M) T^{2}}{2}-A
\end{aligned}
$$

Proof: Since $T R C_{1.2}(T)$ is a strictly pseudo-convex function in $\mathrm{T}$. We have

$$
\begin{aligned}
& \frac{d T R C_{1.2}(T)}{d T}=\frac{1}{\mathrm{~T}^{2}}\left(\mathrm { hT } \left[( P - D ( s , M ) ) \left(\frac{k(1+m-k T)}{2}(1+\right.\right.\right. \\
& \left.\left.2 \log \left(\frac{1+m}{1+m-k T}\right)\right)-\frac{k(1+m-k T)}{2}\right)+ \\
& D(s, M)\left(-\frac{(1+m-T)}{2}-\frac{k(1+m-k T)}{2}\left(2 \log \left(\frac{1+m-k T}{1+m-T}\right)-1\right)+\right. \\
& \left.\left.\frac{(1+m-k T)^{2}}{4}\left(-\frac{2 k}{(1+m-k T)}+\frac{2}{(1+m-T)}\right)\right)\right]-\mathrm{h}[(P- \\
& D(s, M))\left(\frac{k(1+m-k T)}{2}\left(1+2 \log \left(\frac{1+m}{1+m-k T}\right)\right)-\frac{k(1+m-k T)}{2}\right)+ \\
& D(s, M)\left(-\frac{(1+m-T)}{2}-\frac{k(1+m-k T)}{2}\left(2 \log \left(\frac{1+m-k T}{1+m-T}\right)-1\right)+\right. \\
& \left.\left.\frac{(1+m-k T)^{2}}{4}\left(-\frac{2 k}{(1+m-k T)}+\frac{2}{(1+m-T)}\right)\right)\right]+ \\
& \left.\frac{D(s, M)(1-\alpha)(M-N)^{2}\left[s I_{e}-c I_{c}\right]}{2}+\frac{D(s, M) T^{2}\left[\alpha s I_{e}+(1-\alpha) c I_{c}\right]}{2}-A\right)
\end{aligned}
$$

is an increasing function in $\mathrm{T}$, and hence we get

$$
\begin{aligned}
& \frac{d T R C_{1.2}(M-N)}{d T}<\frac{d T R C_{1.2}(M)}{d T} \\
& \Rightarrow \frac{\Delta_{1}}{(M-N)^{2}}<\frac{\Delta_{2}}{M^{2}} \\
& \Rightarrow \Delta_{1}<\Delta_{2}
\end{aligned}
$$

\section{Theorem-4:}

1. If $\Delta_{2}<0$ then $T R C_{1}(T)$ is minimized at $T_{a}^{*}$.

2. If $\Delta_{2}=0$ then $T R C_{1}(T)$ is minimized at $M$.

3. If $\Delta_{1}<0$ then $T R C_{1}(T)$ is minimized at $T_{b}^{*}$.

4. If $\Delta_{1}=0$ then $T R C_{1}(T)$ is minimized at $M-N$.

5. If $\Delta_{1}>0$ then $T R C_{1}(T)$ is minimized at $T_{c}^{*}$.

Proof: We have

$$
\begin{aligned}
& \frac{d T R C_{1.1}(T)}{d T}=\frac{1}{T^{2}}\left(\left(\mathrm { hT } \left[( P - D ( s , M ) ) \left(\frac{k(1+m-k T)}{2}(1+\right.\right.\right.\right. \\
& \left.\left.2 \log \left(\frac{1+m}{1+m-k T}\right)\right)-\frac{k(1+m-k T)}{2}\right)+ \\
& D(s, M)\left(-\frac{(1+m-T)}{2}-\frac{k(1+m-k T)}{2}\left(2 \log \left(\frac{1+m-k T}{1+m-T}\right)-1\right)+\right. \\
& \left.\left.\frac{(1+m-k T)^{2}}{4}\left(-\frac{2 k}{(1+m-k T)}+\frac{2}{(1+m-T)}\right)\right)\right]-\mathrm{h}[(P- \\
& D(s, M))\left(\frac{k(1+m-k T)}{2}\left(1+2 \log \left(\frac{1+m}{1+m-k T}\right)\right)-\frac{k(1+m-k T)}{2}\right)+
\end{aligned}
$$


$D(s, M)\left(-\frac{(1+m-T)}{2}-\frac{k(1+m-k T)}{2}\left(2 \log \left(\frac{1+m-k T}{1+m-T}\right)-1\right)+\right.$
$\left.\left.\frac{(1+m-k T)^{2}}{4}\left(-\frac{2 k}{(1+m-k T)}+\frac{2}{(1+m-T)}\right)\right)\right]+$
$\left.\frac{D(s, M)\left[\alpha M^{2}+(1-\alpha)(M-N)^{2}\right]\left[s I_{e}-c I_{c}\right]}{2}+\frac{c I_{c} D(s, M) T^{2}}{2}-A\right)$

If $\Delta_{2}<0$, then

$\lim _{T \rightarrow \infty} \frac{d T R C_{1.1}(T)}{d T}=\frac{C I_{C} D(s, M)}{2}>0$

And

$\left[\frac{d T R C_{1.1}(T)}{d T}\right]_{T=M}=\frac{\Delta_{2}}{M^{2}}<0$

By applying the Theorem-1 and the Mean Value Theorem, there exists a unique $T_{a}^{*} \in(M, \infty)$ such that $\frac{\operatorname{dTR} C_{1.1}\left(T_{a}^{*}\right)}{d T}=0$. Hence, $T R C_{1.1}(T)$ is minimizing at the unique point $T_{a}^{*}$. By using the analogous argument, we have

$\frac{d T R C_{1.2}(M-N)}{d T}=\frac{\Delta_{1}}{(M-N)^{2}}<\frac{d T R C_{1.2}(M)}{d T}=\frac{\Delta_{2}}{M^{2}}<0$

Which implies that $T R C_{1.2}(M)$ is minimizing at M. Likewise, we get

$\lim _{\delta \rightarrow \infty} \frac{d T R C_{1.3}(\delta)}{d T}<\frac{d T R C_{1.3}(M-N)}{d T}=\frac{\Delta_{1}}{(M-N)^{2}}<0$

Which implies that $\operatorname{TRC}_{1.3}(T)$ is minimizing at M-N. Consequently, we obtain

$T R C_{1.1}\left(T_{a}^{*}\right)<T R C_{1.1}(M)=T R C_{1.2}(M)<T R C_{1.2}(M-$

$N)=T R C_{1.3}(M-N)$

This shows the end of the first part of the theorem. Similarly, remaining of the part of the theorem we can obtain.

\subsection{Determination of Optimal Cycle for the Case of $\mathbf{N} \geq \mathbf{M}$}

By applying the above mentioned results, we separately minimize each of $\mathrm{TRC}_{2 . \mathrm{i}}(\mathrm{T})$ for $\mathrm{i}=1,2$, and obtain the following theoretical results.

\section{Theorem-5:}

1. $T R C_{2.1}(T)$ is a strictly pseudo-convex function in $\mathrm{T}$, and hence there exists a unique minimum solution $T_{d}^{*}$.

2. If $\mathrm{M} \leq T_{d}^{*}$ then $T R C_{2.1}(T)$ subjected to $\mathrm{M} \leq \mathrm{T}$ is minimized at $T_{d}^{*}$.

3. If $\mathrm{M} \geq T_{d}^{*}$ then $T R C_{2.1}(T)$ subjected to $\mathrm{M} \leq \mathrm{T}$ is minimized at $M$.

To find $T_{d}^{*}$, we set $\frac{d T R C_{2.1}(T)}{d T}=0$

$\mathrm{hT}\left[(P-D(s, M))\left(\frac{k(1+m-k T)}{2}\left(1+2 \log \left(\frac{1+m}{1+m-k T}\right)\right)-\right.\right.$ $\left.\frac{k(1+m-k T)}{2}\right)+$

$D(s, M)\left(-\frac{(1+m-T)}{2}-\frac{k(1+m-k T)}{2}\left(2 \log \left(\frac{1+m-k T}{1+m-T}\right)-1\right)+\right.$

$\left.\left.\frac{(1+m-k T)^{2}}{4}\left(-\frac{2 k}{(1+m-k T)}+\frac{2}{(1+m-T)}\right)\right)\right]-\mathrm{h}[(P-$

$D(s, M))\left(\frac{k(1+m-k T)}{2}\left(1+2 \log \left(\frac{1+m}{1+m-k T}\right)\right)-\frac{k(1+m-k T)}{2}\right)+$
$D(s, M)\left(-\frac{(1+m-T)}{2}-\frac{k(1+m-k T)}{2}\left(2 \log \left(\frac{1+m-k T}{1+m-T}\right)-1\right)+\right.$

$\left.\left.\frac{(1+m-k T)^{2}}{4}\left(-\frac{2 k}{(1+m-k T)}+\frac{2}{(1+m-T)}\right)\right)\right]+\frac{D(s, M) \alpha M^{2}\left[s I_{e}-c I_{c}\right]}{2}+$ $\frac{c I_{C} D(s, M) T^{2}}{2}-A=0$

It is obvious from the above theorem that above expression has a unique solution $T_{d}^{*}$. If $T_{d}^{*} \geq M$ then $T R C_{2.1}(T)$ is minimized at $T_{d}^{*}$. Otherwise, $T R C_{2.1}(T)$ is minimized at $\mathrm{M}$.

\section{Theorem-6:}

1. $T R C_{2.2}(T)$ is a strictly pseudo-convex function in $\mathrm{T}$, and hence there exists a unique minimum solution $T_{e}^{*}$.

2. If $\mathrm{M} \geq T_{e}^{*}$ then $T R C_{2.2}(T)$ subjected to $\mathrm{M} \geq \mathrm{T}$ is minimized at $T_{e}^{*}$.

3. If $\mathrm{M} \leq T_{e}^{*}$ then $T R C_{2.1}(T) \quad$ subjected to $\mathrm{M} \geq \mathrm{T}$ is minimized at $M$.

To find $T_{e}^{*}$, we set $\frac{d T R C_{2.2}(T)}{d T}=0$

$\mathrm{hT}\left[(P-D(s, M))\left(\frac{k(1+m-k T)}{2}\left(1+2 \log \left(\frac{1+m}{1+m-k T}\right)\right)-\right.\right.$ $\left.\frac{k(1+m-k T)}{2}\right)+$

$D(s, M)\left(-\frac{(1+m-T)}{2}-\frac{k(1+m-k T)}{2}\left(2 \log \left(\frac{1+m-k T}{1+m-T}\right)-1\right)+\right.$

$\left.\left.\frac{(1+m-k T)^{2}}{4}\left(-\frac{2 k}{(1+m-k T)}+\frac{2}{(1+m-T)}\right)\right)\right]-\mathrm{h}[(P-$

$D(s, M))\left(\frac{k(1+m-k T)}{2}\left(1+2 \log \left(\frac{1+m}{1+m-k T}\right)\right)-\frac{k(1+m-k T)}{2}\right)+$

$D(s, M)\left(-\frac{(1+m-T)}{2}-\right.$

$\frac{k(1+m-k T)}{2}\left(2 \log \left(\frac{1+m-k T}{1+m-T}\right)-1\right)+$

$\left.\left.\frac{(1+m-k T)^{2}}{4}\left(-\frac{2 k}{(1+m-k T)}+\frac{2}{(1+m-T)}\right)\right)\right]+$

$\frac{\alpha s I_{e} D(s, M) T^{2}}{2}+\frac{c I_{c}(1-\alpha) D(s, M) T^{2}}{2}-A=0$

It is obvious from the above theorem that above expression has a unique solution $T_{e}^{*}$. If $T_{e}^{*} \leq M$ then $T R C_{2.2}(T)$ is minimized at $T_{e}^{*}$. Otherwise, $T R C_{2.2}(T)$ is minimized at $\mathrm{M}$.

\section{Theorem-7:}

1. If $\Delta_{3}<0$ then $T R C_{2}(T)$ is minimized at $T_{d}^{*}$

2. If $\Delta_{3}=0$ then $T R C_{2}(T)$ is minimized at $M$

3. If $\Delta_{3}>0$ then $T R C_{2}(T)$ is minimized at $T_{e}^{*}$

Where $\quad \Delta_{3}=\mathrm{hT}\left[(P-D(s, M))\left(\frac{k(1+m-k T)}{2}(1+\right.\right.$

$\left.\left.2 \log \left(\frac{1+m}{1+m-k T}\right)\right)-\frac{k(1+m-k T)}{2}\right)+$

$D(s, M)\left(-\frac{(1+m-T)}{2}-\frac{k(1+m-k T)}{2}\left(2 \log \left(\frac{1+m-k T}{1+m-T}\right)-1\right)+\right.$

$\left.\left.\frac{(1+m-k T)^{2}}{4}\left(-\frac{2 k}{(1+m-k T)}+\frac{2}{(1+m-T)}\right)\right)\right]-\mathrm{h}[(P-$

$D(s, M))\left(\frac{k(1+m-k T)}{2}\left(1+2 \log \left(\frac{1+m}{1+m-k T}\right)\right)-\frac{k(1+m-k T)}{2}\right)+$ 


$$
\begin{aligned}
D(s, M)\left(-\frac{(1+m-T)}{2}\right. & \\
& -\frac{k(1+m-k T)}{2}\left(2 \log \left(\frac{1+m-k T}{1+m-T}\right)\right. \\
& -1) \\
& +\frac{(1+m-k T)^{2}}{4}\left(-\frac{2 k}{(1+m-k T)}\right. \\
& \left.\left.\left.+\frac{2}{(1+m-T)}\right)\right)\right]+\frac{\alpha s I_{e} D(s, M) M^{2}}{2} \\
& +\frac{c I_{c}(1-\alpha) D(s, M) M^{2}}{2}-A
\end{aligned}
$$

\section{SOME SPECIAL CASES}

5.1 Goyal's Model: If the production rate is infinite and the potential worth of the product does not change in infinite time i.e., $m \rightarrow 0$. And also $\mathrm{s}=\mathrm{c}, I_{c}>I_{e}, N \rightarrow 0$ (it means that the supplier would offer the manufacturer a delay period but the manufacturer would not offer the delay period to wholesaler) that is one level credit, $\alpha \rightarrow 0$, demand does not depends on selling price and trade credit then this inventory model is identical to that of Goyal (1985).

5.2 Teng's Model: If the production rate is infinite and the potential worth of the product does not change in infinite time i.e., $m \rightarrow 0$. And also $N \rightarrow 0$ ( it means that the supplier would offer the manufacturer a delay period but the manufacturer would not offer the delay period to wholesaler) that is one level credit, $\alpha \rightarrow 0$, demand does not depends on selling price and trade credit then this inventory model is identical to that of Teng (2002).

5.3 Huang's Model: If the production rate is infinite and the potential worth of the product does not change in infinite time i.e., $m \rightarrow 0$. So s=c, $I_{c}>I_{e}, \alpha \rightarrow 0$, demand does not depends on selling price and trade credit then this inventory model is identical to that of Huang (2003).

5.4 Teng and Goyal's Model: If the production rate is infinite and the potential worth of the product does not change in infinite time i.e., $m \rightarrow 0 . \alpha \rightarrow 0$, demand does not depends on selling price and trade credit then this inventory model is identical to that of Teng and Goyal (2007).

5.5 Teng's Model: If the production rate is infinite and the potential worth of the product does not change in infinite time i.e., $m \rightarrow 0$. demand does not depends on selling price and trade credit then this inventory model is identical to that of Teng (1985).

5.6 Chen and Teng's Model: If the production rate is infinite and $N \rightarrow 0$ (it means that the supplier would offer the manufacturer a delay period but the manufacturer would not offer the delay period to wholesaler) that is one level credit, $\alpha \rightarrow 0$, demand does not depends on selling price and trade credit then this inventory model is identical to that of Chen and Teng (2014).

5.7 Wu and Chan's Model: If the production rate is infinite and demand does not depends on selling price and trade credit then this inventory model is identical to that of $\mathbf{W u}$ and Chan (2014).

\section{NUMERICAL ANALYSIS}

Example-1. If $a=1000, b=0.08, d=2000, \beta=0.09, c=\$ 50$ per unit, $\mathrm{h}=\$ 15$ per unit, $\mathrm{I}_{\mathrm{c}}=0.15, \mathrm{I}_{\mathrm{e}}=0.10, \mathrm{~N}=0.05, \alpha=0.5, \mathrm{k}=0.65$, $\mathrm{m}=1$
Table-1: Optimal Policy in case of $M>N$

\begin{tabular}{cccc}
\hline $\begin{array}{c}\text { Values of } \\
\text { Parameter/Cases }\end{array}$ & $\mathbf{1 . 1}$ & $\mathbf{1 . 2}$ & $\mathbf{1 . 3}$ \\
\hline $\mathbf{P}$ & 2800 & 3700 & 4300 \\
$\mathbf{M}$ & 0.9 & 0.9 & 0.12 \\
$\mathbf{A}$ & 135 & 90 & 165 \\
$\mathbf{S}$ & 70 & 85 & 129 \\
$\boldsymbol{\Delta}_{\mathbf{1}}$ & -145.76 & -92.98 & 48.98 \\
$\boldsymbol{\Delta}_{\mathbf{2}}$ & -80.83 & 20.98 & 278.97 \\
$\mathbf{T}^{*}$ & $0.12\left(\mathrm{~T}_{\mathrm{a}}\right)$ & $0.08\left(\mathrm{~T}_{\mathrm{b}}\right)$ & 0.07 \\
& & & $\left(\mathrm{~T}_{\mathrm{c}}\right)$ \\
\hline $\mathbf{T R C}(\$)$ & 2123.95 & 1782.98 & 724.89
\end{tabular}

By using Theorem-4, the optimal solution on three different sets of parameters as shown in Table-1 can easily obtained.

Example-2. If $a=1000, b=0.08, d=2000, \beta=0.09, I_{c}=0.15$, $\mathrm{I}_{\mathrm{e}}=0.10, \mathrm{~h}=\$ 15$ per unit, $\mathrm{c}=\$ 50$ per unit, $\mathrm{N}=0.05, \alpha=0.5$, $\mathrm{k}=0.65, \mathrm{~m}=1$

Table-2: Optimal Policy in case of $M \leq N$

\begin{tabular}{ccc}
\hline $\begin{array}{c}\text { Values of } \\
\text { Parameter/Cases }\end{array}$ & $\mathbf{2 . 1}$ & $\mathbf{2 . 2}$ \\
\hline $\mathbf{P}$ & 3200 & 4700 \\
$\mathbf{M}$ & 0.08 & 0.9 \\
$\mathbf{A}$ & 155 & 90 \\
$\mathbf{S}$ & 70 & 85 \\
$\boldsymbol{\Delta}_{\mathbf{3}}$ & -145.76 & 42.98 \\
$\mathbf{T}^{*}$ & $0.14\left(\mathrm{~T}_{\mathrm{d}}\right)$ & $0.07\left(\mathrm{~T}_{\mathrm{e}}\right)$ \\
TRC(\$) $^{*}$ & 3233.15 & 2671.18 \\
\hline
\end{tabular}

By using Theorem-5, the optimal solution on two different sets of parameters as shown in Table- 2 can be easily obtained.

\subsection{Discussion:}

Concept of two-level trade credit and lifetime of the manufactured product has received a very little attention by the researchers while taking the decision regarding the manufacturing system. In this paper, manufacturing inventory model has been developed by assuming that the deteriorating items have maximum lifetime and the manufacturer holds the powerful position in the industry. So manufacturer can obtain the full trade credit offered by the supplier and manufacturer just offers partial trade credit to his/her wholesaler. It is assumed that demand can be stimulated by credit period and also affected by the selling price. 


\section{CONCLUSION}

Our proposed production inventory model forms a general framework that includes many previous model as special cases such as Teng (1985), Goyal (1985), Teng (2002), Huang (2003), Teng and Goyal (2007), Chen and Teng (2014), Wu and Chan (2014). Furthermore, we have proposed theorems to find the optimal cycle time. Numerical examples are presented to illustrate the proposed theorems for finding the optimal cycle length. This model can be applied in many practical situations. Manufacturer can use trade credit as competitive weapon to attract the wholesaler. By doing so, manufacturer can reduce the burden of holding cost. By flexible selling price system can also produce the effect on demand and hence the total inventory cost. Thus results of the paper not only provide a valuable reference for decisionmakers in planning and controlling the manufacturing system but also provide a useful model for many organizations that use the decision rule to improve their total operational cost.

\subsection{Future Work}

There are several promising areas in which direction this model can be extended. One of the fertile areas is to consider imprecise parameters in place of precise one. One can extend this model by considering three different players such as manufacturer, retailer and suppler to integrated systems.

\section{REFERENCES}

[1] Bera, S., Kar, S., Chakraborti, T., and Sinha, B. (2014). An Inventory Model for Deteriorating Items under Conditionally Permissible Delay in Payments Depending on the Order Quantity. Applied Mathematics, Vol.5, pp.2675-2695.

[2] Bhunia, A.K., Jaggi, C.K., Sharma, A., and Sharma, R. (2014). A two-warehouse inventory model for deteriorating items under permissible delay in payment with partial backlogging. Applied Mathematics and Computation, Vol. 232, pp. 1125-1137.

[3] Chand, S., and Ward, J. (1987). A note on economic order quantity under conditions of permissible delay in payments. Journal of the Operational Research Society, Vol. 38, pp. 83-84.

[4] Chen, S.C., and Teng, J.T. (2014). Retailer's optimal ordering policy for deteriorating items with maximum lifetime under supplier's trade credit financing. Applied Mathematical Modelling, Vol. 38, pp. 4049-4061.

[5] Chen, S.C., Teng, J.T., and Skouri, K. (2013). Economic production quantity models for deteriorating items with up-stream full trade credit and down-stream partial trade credits. International Journal of Production Economics, Vol. 155, pp. 302-309.

[6] Chung, K. J., Goyal, S. K., and Huang, Y. F. (2005). The optimal inventory policies under permissible delay in payments depending on the ordering quantity. International Journal of Production Economics, Vol. 95, pp. 203-213.

[7] Chung, K.J. (2013). The EPQ model under conditions of two levels of trade credit and limited storage capacity in supply chain. International Journal of Systems Science, Vol. 44, pp. 1675-1691.
[8] Covert, R.B., and Philip, G.S. (1973). An EOQ model with Weibull distribution deterioration. AIIE Trans. Vol. 5, pp. 323-326.

[9] Dave, U., and Patel, L.K. (1981). (T,S $\mathrm{S}_{1}$ ) policy inventory model for deteriorating items with time proportional demand. Journal of Operational Research Society. Vol. 35, pp. 1013-1019.

[10] Dye, C.Y., Ouyang, L.Y., and Hsieh, T.P. (2007). Inventory and pricing strategies for deteriorating items with shortages: A discounted cash flow approach. Computers \& Industrial Engineering, Vol. 52, pp. 29-40.

[11] Feng, H., Jun, L., and Zhao, D. (2013). Retailer's optimal replenishment and payment policy in EPQ model under cash discount and two-level trade credit policy. Applied Mathematical Modelling, Vol. 37, pp. 3322-3399.

[12] Ghare, P.M., and Schrader, G.F. (1963). A model for an exponential decaying inventory. Journal of Industrial Engineering, Vol. 14, pp. 238-243.

[13] Goyal, S. K. (1985). Economic order quantity under conditions of permissible delay in payments. Journal of Operation Research Society, Vol. 36, pp. 335-338.

[14] Goyal, S.K., and Giri, B.C. (2001). Recent trends in modeling of deteriorating inventory. European Journal of Operational Research. Vol. 134, pp. 1228-1246.

[15] Ho, C. H., Ouyang, L. Y., and Su, C. H. (2008). Optimal pricing, shipment and payment policy for an integrated supplier-buyer inventory model with two-part trade credit. European Journal of Operational Research, Vol. 187, pp. 496-510.

[16] Huang, Y. F. (2003). Optimal retailer's ordering policies in the EOQ model under trade credit financing. Journal of the Operational Research Society, Vol. 54, pp.10111015.

[17] Huang, Y. F. (2004). Optimal retailer's replenishment policy for the EPQ model under supplier's trade credit policy. Production Planning and Control, Vol. 15, pp. 27-33.

[18] Huang, Y. F. (2006). An inventory model under twolevels of trade credit and limited storage space derived without derivatives. Applied Mathematical Modeling, Vol. 30, pp. 418-436.

[19] Huang, Y. F. (2007). Optimal retailer's replenishment decisions in the EPQ model under two levels of trade credit policy. European Journal of Operational Research, Vol. 176, pp. 1577-1591.

[20] Kreng, V. B., and Tan, S. J. (2010). The optimal replenishment decisions under two levels of trade credit policy depending on the order quantity. Expert System with Applications, Vol. 37, pp. 5514-5522.

[21] Liao, J. J. (2008). An EOQ model with noninstantaneous receipt and exponentially deteriorating items under two-level trade credit policy. International Journal of Production Economics, Vol. 113, pp. 852861.

[22] Mahata, G. C., and Goswami, A. (2007). An EOQ model for deteriorating items under trade credit financing in the fuzzy sense. Production Planning and Control, Vol. 18(8), pp. 681-692. 
[23] Min, J., Zhou, Y. W., and Zhao, J. (2010). An inventory model for deteriorating items under stock-dependent demand and two-level trade credit. Applied Mathematical Modelling, Vol. 34, pp. 3273-3285.

[24] Rao, K.S., and Rao, S. E. (2015). Inventory model under permissible delay in payments and inflation with generalised Pareto lifetime. International Journal of Procurement Management, Vol. 8(1-2), pp. 202-226.

[25] Shastri, A., Singh, S.R., Yadav, D., Gupta. S. (2014) Supply chain management for two-level trade credit financing with selling price dependent demand under the effect of preservation technology. International Journal of Procurement Management, Vol. 7(6), pp. 695-717.

[26] Shinn, S. W., Hwang, H. P., and Sung, S. (1996). Joint price and lot size determination under conditions of permissible delay in payments and quantity discounts for freight cost. European Journal of Operational Research, Vol. 91, pp. 528-542.

[27] Singh, Y., Malik, A. K., and Kumar, S. (2015). An Inflation Induced Stock-Dependent Demand Inventory Model with Permissible delay in Payment. International Journal of Computer Applications, Vol. 96(25), pp. 1418.

[28] Tayal, S., Singh, S and Sharma, R. (2015). An inventory model for deteriorating items with seasonal products and an option of an alternative market. Uncertain Supply Chain Management, Vol. 3(1), pp. 69-86.
[29] Teng, J. T., Chang, C. T., and Goyal, S. K. (2005). Optimal pricing and ordering policy under permissible delay in payments. International Journal of Production Economics, Vol. 97, pp. 121-129.

[30] Teng, J.T., Chern, M.S., and Yang, H.L., and Wang, Y.J. (2002). An optimal replenishment policy for deteriorating items with time-varying demand and partial backlogging. Operational Research Letter. Vol. 192(1), pp. 387-393.

[31] Tsao, Y. C. (2009). Retailer's optimal ordering and discounting policies under advance sales discount and trade credits. Computers and Industrial Engineering, Vol. 56, pp. 208-215.

[32] Yadav, D., Singh, S.R., and Kumari, R. (2012) Inventory Model of Deteriorating items with TwoWarehouse and Stock Dependent Demand using Genetic Algorithm in Fuzzy Environment. Yugoslav Journal of Operations Research, Vol. 22(1), pp. 51-78.

[33] Yadav, D., Singh, S.R., and Kumari, R. (2015). Retailer's optimal policy under inflation in fuzzy environment with trade credit. International Journal of Systems Science, Vol. 46(4), pp. 754-762.

[34] Zhou, Y.W., Zhong, Y.G., and Wahab, M.I.M. (2013). How to make the replenishment and payment strategy under flexible two-part trade credit. Comput. Oper. Res. Vol. 40, pp. 1328-1338. 